
\title{
Research Sulure \\ Rest Cardiac Power Predicts All-cause Death and Heart Failure Hospitalization in Heart Failure Patients With Preserved Ejection Fraction
}

\section{Jianqiao Chen}

Medical School of Chinese PLA: Chinese PLA General Hospital

Huiying Li

Medical School of Chinese PLA: Chinese PLA General Hospital

Benchuan Hao

Medical School of Chinese PLA: Chinese PLA General Hospital

Yulun Cai

Medical School of Chinese PLA: Chinese PLA General Hospital

Shiqi Wang

Zhengzhou First People Hospital

Hongbin Liu (D lhbplagh301@163.com )

Chinese PLA General Hospital https://orcid.org/0000-0002-7139-9851

\section{Original investigation}

Keywords: Cardiac power, echocardiography, heart failure with preserved ejection fraction, outcomes

Posted Date: April 20th, 2021

DOI: https://doi.org/10.21203/rs.3.rs-430111/v1

License: (c) (i) This work is licensed under a Creative Commons Attribution 4.0 International License. Read Full License 


\section{Abstract}

Background: Cardiac power as an integrated indicator of cardiac performance that incorporates both pressure and volume factors. It has been studied in patients with reduced left ventricular (LV) ejection fraction (EF), and in the present study we aimed to explore its significance and role in predicting adverse outcome in patients with heart failure with preserved ejection fraction (HFpEF).

Methods: This retrospective cohort study included 2089 community-dwelling patients with HFpEF and without significant valve diseases or right ventricular dysfunction. We normalized cardiac power to LV mass and expressed it in W/100 g of LV myocardium. Univariate analysis with log-rank test and multivariate analysis with Cox regression model were used to evaluate the association between rest cardiac power/mass and all-cause death and heart failure (HF) hospitalization.

Results: After a median follow-up of 4.4 (0.5-10.1) years, 331 (15.84\%) experienced all-cause death and 391 (18.72\%) experienced HF hospitalization. Patients with the lower rest power/mass were older and had higher New York Heart Association class, N-terminal pro-brain natriuretic peptide (NT-proBNP) level and more comorbidities. After adjusting for multiple covariates, rest power/mass $\leq 0.7 \mathrm{~W} / \mathrm{m}^{2}$ was independently associated with all-cause death and HF hospitalization, with the hazard ratio (HR) of 1.753 [95\% confidence interval $(\mathrm{Cl}) 1.394-2.203, P<0.001]$ and 1.266 (95\% $\mathrm{Cl} 1.033-1.551, P=0.023)$, respectively. The $\mathrm{C}$ statistic increased significantly when the rest cardiac power/mass were incorporated into a model with established risk factors. For all-cause death, the continuous net reclassification index (NRI) after adding rest cardiac power/mass in the model with established risk factors and NT-proBNP was $17.0 \%(95 \% \mathrm{Cl} 11.4-28.3, P=0.04)$, and the integrated discrimination index (IDI) was $2.3 \%(95 \% \mathrm{Cl}$ 0.7-8.7, $P=0.02)$; for HF hospitalization, the corresponding continuous NRI and IDI were $6.0 \%(95 \% \mathrm{Cl}$ 4.7-15.2, $P=0.026)$ and $1.7 \%(95 \% \mathrm{Cl} 1.2-4.3, P=0.007)$, respectively.

Conclusion: Rest cardiac power by non-invasive echocardiography is independently associated with risks of adverse outcomes in patients with HFpEF and provides incremental prognostic information.

\section{Introduction}

Chronic heart failure (HF) is characterized by the declined cardiac systolic and/or diastolic function, resulting in a primary cause of morbidity and mortality all over the world [1]. The main concern about the HF management lies in how to accurately and comprehensively evaluate the cardiac function, especially left ventricular (LV) function, as LV is responsible for most of the physiological functions of the heart. When evaluating the LV function, clinical physicians usually adopt the traditional indexes including LV ejection fraction (EF) and cardiac output. Although well known, these measurements may fail to provide a comprehensive assessment of LV function. In addition, nearly a half of HF patients have preserved EF (namely HFpEF)[2]. EF thus seems unable to identify high-risk individuals among HF patients.

Cardiac power refers to the rate at which the heart pumps blood out and deliver it to the periphery [3]. Thus, it is an integrative and quantitative indicator of overall cardiac performance that combines cardiac 
pressure and volume loads. Normally, $3 \mathrm{mmHg}$ of right atrial pressure, $120 / 80 \mathrm{mmHg}$ of arterial pressure, and $5 \mathrm{~L} /$ min of cardiac output produce the $\sim 1 \mathrm{~W}$ of resting cardiac power. Some studies have shown that higher rest and peak cardiac power are associated with mortality in patients with chronic and advance HF [4-6]. Furthermore, a retrospective study conducted by Anand et al. [7] showed that, in patients with normal EF and no HF undergoing exercise stress echocardiography, higher cardiac power was independently associated with the lower prevalence of complications, as well as the lower the all-cause death and the incidence of subsequent HF, suggesting the potential prognostic value of cardiac power.

Whereas cardiac power has been well studied in HF patients with reduced EF (namely HFrEF) and those with normal EF but no HF, its significance and role in predicting adverse outcome in patients with HFpEF remains unclear. Thus, in this study we aimed to evaluate the role of cardiac power indexed to LV mass in patients with stable HFpEF.

\section{Methods}

This study was approved by the Ethics Board of the Chinese PLA General Hospital and was conducted in line with the ethical guidelines of the 1975 Declaration of Helsinki. Written informed consent was obtained from each patient. The datasets used and/or analyzed during the current study are available from the corresponding author on reasonable request.

\subsection{Participants}

This retrospective cohort study recruited 3943 community dwellers who received physical examination at the Chinese PLA General Hospital (Beijing, China) from January 2008 to July 2019. Through physical examination data, electronic medical record and the confirmation of diagnosis by two cardiologists, we referred to the 2016 European Society of Cardiology guidelines [8] and selected HFpEF patients. The diagnosis of HFpEF should satisfy the following criteria: patients with (i) HF syndromes and/or signs, (ii) LVEF $\geq 50 \%$, (iii) N-terminal pro-brain natriuretic peptide (NT-proBNP) $>125 \mathrm{pg} / \mathrm{mL}$ in sinus rhythm and > $375 \mathrm{pg} / \mathrm{mL}$ in atrial fibrillation, and (iv) evidence of left atrium enlargement and/or left ventricle hypertrophy or diastolic dysfunction. Besides, eligible HFpEF patients had a history of HF hospitalization and were stable and well-compensated without medication changes for at least 6 weeks prior to enrollment.

Patients who had one of the following conditions were excluded: EF less than $50 \%$ at rest, moderate or severe right ventricular dysfunction, severe valvular disease, hospitalization for uncompensated HF or unstable coronary heart disease in the prior 6 weeks, heart transplant, metastatic malignant tumor, severe liver disease or receiving palliative care. We collected patient detailed medical history, baseline clinical characteristics, laboratory indexes and echocardiographic parameters on the day of the physical examination. After excluding ineligible patients, we got a final sample of $2089 \mathrm{HFpEF}$ patients for next analysis. And the flowchart regarding the detailed data process is shown in Fig. 1.

\subsection{Rest cardiac power and comorbidity score}


Cardiac power normalized by LV mass at rest was calculated by following formulas:

Rest cardiac power $/$ mass $=0.222 \cdot$ cardiac output $\cdot$ mean blood pressure $(\mathrm{BP}) / \mathrm{LV}$ mass

Cardiac output $=$ stroke volume $\cdot$ heart rate $(H R)$

Mean arterial pressure $=$ Diastolic $\mathrm{BP}+1 / 3 \cdot$ Systolic $\mathrm{BP}$

in which 0.222 is the conversion constant to W/100 g of LV myocardium.[6] In each patient, stroke volume was equals to the difference value of LV end-systolic volume and LV end-diastolic volume by 2D echocardiography, assuming normal LV geometry, which is a reasonable assumption in the situation of normal EF, no right ventricular dysfunction, and no severe valvular diseases.[7]

To evaluate the severity of patient comorbidities, we defined comorbidity score as the number of patient comorbidities referring to the Charlson Comorbidity Index (CCl). [9] For the present study, we included the comorbidities with 1 point in $\mathrm{CCl}$ (myocardial infarction, peripheral vascular disease, cerebrovascular disease, dementia, chronic lung disease, connective tissue disease, ulcer disease, mild liver disease and diabetes), anemia, hypertension and atrial fibrillation, and excluded the comorbidities scored $\geq 2$ points in $\mathrm{CCl}$ (such as severe liver disease, metastatic tumors, leukemia, etc.). As our analysis was entirely among HFpEF patients, the 1 point added for HF was not included in the final number of comorbidities.

\subsection{Follow-up and outcomes}

Until December 31, 2020, all patients were followed up via telephone or medical record every 6 months for all-cause death or HF hospitalization. Furthermore, we contacted the attending physician of each patient with event to reconfirm their outcome. For patients who did not have an event, survival time was defined as the period from the day of physical examination to the last date of follow-up.

\subsection{Statistical analysis}

Patient baseline characteristics are presented as frequencies (\%) and mean \pm standard deviation (SD) for categorical and continuous variables, respectively. We log transformed the continuous variables without normal distribution, i.e., NT-proBNP. The difference of continuous variables and categorical variables between groups were compared via Student's t test and Chi square test, respectively. Spearman's correlation analysis was performed to evaluate the correlations between rest cardiac power/mass and clinical variables. Multiple linear regression was performed to identify the factors independently associated with rest cardiac power/mass. Median values of rest cardiac power/mass and log NT-proBNP were considered as cutoffs. The log-rank test was used to compare survival times on Kaplan-Meier curves across different groups. The prognostic value of rest cardiac power/mass was evaluated by using Cox proportional hazards model adjusted for the following covariates: age, sex, body mass index (BMI, calculated by weight divided by the square of height), New York Heart Association (NYHA) class, comorbidity score, estimated glomerular filtration rate (eGFR, calculated by a modified Modification of Diet in Renal Disease), angiotensin-converting enzyme inhibitors (ACEI)/angiotensin receptor antagonist (ARB), beta blocker and aldosterone antagonist. The prognostic discrimination of rest cardiac 
power/mass was assessed by comparing the incremental improvement of the Harrell's C-statistic, as well as the integrated discrimination improvement (IDI) and the continuous net re-classification improvement (NRI) at the event rate. Sensitivity analysis was further performed to explore the association between the rest cardiac power/mass and the all-cause death and $\mathrm{HF}$ hospitalization among the following subgroups: age ( $<75$ or $\geq 75$ years), BMl ( $<18.5 \mathrm{~kg} / \mathrm{m}^{2}, 18.5-23.9 \mathrm{~kg} / \mathrm{m}^{2}, 24-27.9 \mathrm{~kg} / \mathrm{m}^{2}$ or $\left.\geq 28 \mathrm{~kg} / \mathrm{m}^{2}\right), \mathrm{NYHA}$ class (class I + II or class III + IV), comorbidity score ( $0-3$ or $\geq 4)$, eGFR $\left(<60 \mathrm{~mL} / \mathrm{min} / 1.73 \mathrm{~m}^{2}\right.$ or $\geq 60$ $\mathrm{mL} / \mathrm{min} / 1.73 \mathrm{~m}^{2}$ ) and log NT-proBNP (<2.5 or $\geq 2.5$ ). R 4.0.3 software (Institute for Statistics and Mathematics, Vienna, Austria; http://cran.r-project.org) and SPSS 26.0 software (IBM Corporation, Armonk, NY, USA) was used to perform statistical analyses. A $P$ value $<0.05$ was considered significant.

\section{Results}

\subsection{Baseline characteristics}

Baseline measurements of rest cardiac power/mass were available for 2089 patients. The median value of rest cardiac power/mass was $0.7 \mathrm{~W} / \mathrm{m}^{2}$, which was used as cutoff for grouping. The patients with lower rest cardiac power/mass were older, and had higher NYHA class, NT-proBNP level and more comorbidities. Detailed baseline characteristics are shown in Table 1. 
Table 1

Baseline characteristics of patients with HFpEF

\begin{tabular}{|c|c|c|c|}
\hline & $\begin{array}{l}\text { Rest cardiac power/mass }<0.7 \\
\mathrm{~W} / \mathrm{m}^{2}(\mathrm{~N}=1021)\end{array}$ & $\begin{array}{l}\text { Rest cardiac power/mass } \geq 0.7 \\
\mathrm{~W} / \mathrm{m}^{2}(\mathrm{~N}=1068)\end{array}$ & $\begin{array}{l}P \text { - } \\
\text { value }\end{array}$ \\
\hline Age (years) & $77.90 \pm 11.37$ & $74.78 \pm 11.39$ & 0.046 \\
\hline Male (\%) & $983(96.28)$ & 1018(95.32) & 0.163 \\
\hline Smoking (\%) & $376(37.12)$ & $386(36.28)$ & 0.363 \\
\hline Alcohol (\%) & $326(32.06)$ & $339(31.83)$ & 0.475 \\
\hline WC (cm) & $92.23 \pm 8.77$ & $92.30 \pm 8.65$ & 0.487 \\
\hline BMI $\left(\mathrm{kg} / \mathrm{m}^{2}\right)$ & $24.48 \pm 2.93$ & $24.52 \pm 3.21$ & 0.476 \\
\hline $\mathrm{SBP}(\mathrm{mmHg})$ & $128.665 \pm 16.722$ & $137.396 \pm 16.603$ & 0.648 \\
\hline $\mathrm{DBP}(\mathrm{mmHg})$ & $66.66 \pm 8.80$ & $75.41 \pm 9.50$ & 0.048 \\
\hline $\mathrm{HR}(\mathrm{bpm})$ & $66.56 \pm 8.50$ & $77.10 \pm 10.49$ & <. 001 \\
\hline NYHA class & & & 0.031 \\
\hline I or II & $594(58.18)$ & $656(61.42)$ & \\
\hline III or IV & $427(41.82)$ & $412(38.58)$ & \\
\hline $\begin{array}{l}\text { eGFR } \\
(\mathrm{mL} / \mathrm{min} / 1.73 \\
\left.\mathrm{m}^{2}\right)\end{array}$ & $87.79 \pm 24.94$ & $90.36 \pm 23.52$ & 0.572 \\
\hline FBG (mmol/L) & $5.78 \pm 1.61$ & $5.81 \pm 1.72$ & 0.789 \\
\hline $\begin{array}{l}\text { Log NT-proBNP } \\
(\mathrm{pg} / \mathrm{mL})\end{array}$ & $2.45 \pm 0.56$ & $2.30 \pm 0.55$ & $\hat{0}_{0.001}$ \\
\hline $\begin{array}{l}\text { Comorbidity } \\
\text { score }\end{array}$ & $3.52 \pm 1.90$ & $3.15 \pm 1.81$ & 0.015 \\
\hline \multicolumn{4}{|l|}{ Medication (\%) } \\
\hline ACEI/ARB & $379(37.12)$ & $370(34.64)$ & 0.128 \\
\hline Beta blocker & $292(28.60)$ & $308(28.84)$ & 0.471 \\
\hline
\end{tabular}

Data are expressed as mean + SD or median and number (\%). HFpEF indicates heart failure with preserved ejection fraction; WC, waist circumference; BMI, body mass index; SBP, systolic blood pressure; DBP, diastolic blood pressure; HR, heart rate; NYHA, New York Heart Association; eGFR, estimated glomerular filtration rate; FBG, fasting blood glucose; NT-proBNP, N-terminal pro-brain natriuretic peptide; $A C E I$, angiotensin-converting enzyme inhibitors; $A R B$, angiotensin receptor antagonist. 


\begin{tabular}{|llll|}
\hline & $\begin{array}{l}\text { Rest cardiac power/mass }<0.7 \\
\mathrm{~W} / \mathrm{m}^{2}(\mathrm{~N}=1021)\end{array}$ & $\begin{array}{l}\text { Rest cardiac power/mass } \geq 0.7 \\
\mathrm{~W} / \mathrm{m}^{2}(\mathrm{~N}=1068)\end{array}$ & $\begin{array}{c}P \\
\text { value }\end{array}$ \\
\hline Diuretic & $154(15.08)$ & $101(9.46)$ & 0.001 \\
\hline Statins & $701(68.66)$ & $626(58.61)$ & 0.001 \\
\hline $\begin{array}{l}\text { Aldosterone } \\
\text { antagonist }\end{array}$ & $49(4.80)$ & $32(3.00)$ & 0.021 \\
\hline $\begin{array}{l}\text { Data are expressed as mean + SD or median and number (\%). HFpEF indicates heart failure with } \\
\text { preserved ejection fraction; WC, waist circumference; BMl, body mass index; SBP, systolic blood } \\
\text { pressure; DBP, diastolic blood pressure; HR, heart rate; NYHA, New York Heart Association; eGFR, } \\
\text { estimated glomerular filtration rate; FBG, fasting blood glucose; NT-proBNP, N-terminal pro-brain } \\
\text { natriuretic peptide; ACEl, angiotensin-converting enzyme inhibitors; ARB, angiotensin receptor } \\
\text { antagonist. }\end{array}$ & \\
\hline
\end{tabular}

\subsection{Correlations of rest cardiac power/mass with other clinical and biochemical factors}

Decreasing levels of rest cardiac power/mass were correlated with increased age, log NT-proBNP and comorbidity score, lower eGFR and fasting blood glucose, and larger possibility of male and using ACEI/ARB and aldosterone antagonist (Table 2). All characteristics in Table 2 were included in multiple regression analysis, which showed that rest cardiac power/mass as the dependent variable was independently associated with age $(P=0.039)$, comorbidity score $(P=0.028)$, log NT-proBNP $(P<0.001)$ and medication of beta blocker $(P=0.014)$ and aldosterone antagonist $(P=0.006)$ 
Table 2

Spearman's correlation and multiple linear regression between rest cardiac power/mass and clinical and biochemical variables

\begin{tabular}{|c|c|c|c|c|}
\hline \multirow[t]{2}{*}{ Variables } & \multicolumn{2}{|c|}{ Spearman correlation } & \multicolumn{2}{|c|}{ Multiple linear regression } \\
\hline & Coefficient & $P$ & Standardized $\beta$ & $P$ \\
\hline Age (years) & -0.155 & $<0.001$ & -0.063 & 0.039 \\
\hline Male & -0.024 & 0.271 & -0.042 & 0.063 \\
\hline Smoking & 0.015 & 0.499 & 0.007 & 0.771 \\
\hline Alcohol & 0.015 & 0.493 & 0.019 & 0.433 \\
\hline WC (cm) & 0.024 & 0.283 & 0.020 & 0.387 \\
\hline $\mathrm{BMI}\left(\mathrm{kg} / \mathrm{m}^{2}\right)$ & -0.042 & 0.058 & -0.045 & 0.056 \\
\hline $\mathrm{SBP}(\mathrm{mmHg})$ & 0.015 & 0.501 & 0.006 & 0.805 \\
\hline $\mathrm{DBP}(\mathrm{mmHg})$ & 0.026 & 0.236 & 0.020 & 0.437 \\
\hline $\mathrm{HR}(\mathrm{bpm})$ & 0.008 & 0.710 & 0.023 & 0.316 \\
\hline NYHA class & -0.042 & 0.053 & 0.010 & 0.674 \\
\hline $\operatorname{eGFR}\left(\mathrm{mL} / \mathrm{min} / 1.73 \mathrm{~m}^{2}\right)$ & 0.086 & $<0.001$ & 0.005 & 0.830 \\
\hline FBG (mmol/L) & 0.067 & 0.002 & 0.073 & 0.201 \\
\hline Log NT-proBNP (pg/mL) & -0.162 & $<0.001$ & -0.102 & $<0.001$ \\
\hline Comorbidity score & -0.138 & $<0.001$ & -0.062 & 0.028 \\
\hline \multicolumn{5}{|l|}{ Medication (\%) } \\
\hline ACEI/ARB & -0.051 & 0.02 & -0.028 & 0.244 \\
\hline Beta blocker & -0.004 & 0.856 & 0.057 & 0.014 \\
\hline Diuretic & -0.011 & 0.630 & -0.062 & 0.106 \\
\hline Statins & 0.029 & 0.184 & 0.000 & 0.994 \\
\hline Aldosterone antagonist & -0.084 & $<0.001$ & -0.062 & 0.006 \\
\hline
\end{tabular}

\subsection{Clinical outcomes}

The 2089 HFpEF patients were followed up for 4.4 years on average, with no patients lost to follow-up. Among them, 331 (15.84\%) experienced all-cause death and 391 (18.72\%) experienced HF 
rehospitalization. $216(65.26 \%)$ patients with all-cause death and $225(57.54 \%)$ patients with HF hospitalization had values of rest cardiac power/mass below $0.7 \mathrm{~W} / \mathrm{m}^{2}$.

Kaplan-Meier curves of the incidences of all-cause death and HF hospitalization are presented in Fig. 2 and Fig. 3 across different category methods. The incidences of adverse outcomes in patients with rest cardiac power/mass $\leq 0.7 \mathrm{~W} / \mathrm{m}^{2}$ were significantly higher than those with rest cardiac power $/$ mass $>0.7$ $\mathrm{W} / \mathrm{m}^{2}$ (each log-rank $P<0.001$, Fig. 2). To determine the potential utility of rest cardiac power/mass and NT-proBNP, we divided the cohort into four groups based upon the median values of rest cardiac power/mass and NT-proBNP (Fig. 3). As we can see, patients with either a lower rest cardiac power/mass or higher NT-proBNP level had an increased risk compared with the reference group that had higher rest cardiac power/mass and lower NT-proBNP $(P<0.001)$.

Patients with lower rest cardiac power/mass and higher NT-proBNP had a markedly increased risk [for allcause death, hazard ratio (HR) 6.587, 95\% confidential interval (Cl) 4.684-9.264, $P<0.001$; and for HF hospitalization, HR 4.577, 95\% $\mathrm{Cl} 3.443-6.085, P<0.001]$, indicating that rest cardiac power/mass and NT-proBNP together are more effective than either indicator in identifying a high-risk subgroup.

After adjustment for commonly recognized risk factors (age, sex, BMI, NYHA class, comorbidity score, eGFR, ACEI/ARB, beta blocker and aldosterone antagonist, log NT-proBNP), in multivariate analysis, rest cardiac power/mass $\leq 0.7 \mathrm{~W} / \mathrm{m}^{2}$ was independently associated with the incidence of all-cause death and HF hospitalization with the HRs of $1.753(95 \% \mathrm{Cl} 1.394-2.203 ; P<0.001)$ and $1.266(95 \% \mathrm{Cl} 1.033-$ $1.551, P=0.023$ ), respectively (Table 3 ). 
Table 3

HRs and $95 \% \mathrm{Cls}$ of outcomes according to the categories of rest cardiac power/mass

\begin{tabular}{|c|c|c|c|}
\hline Outcomes & $\begin{array}{l}\text { Rest cardiac power/mass } \leq \\
0.7 \mathrm{~W} / \mathrm{m}^{2}\end{array}$ & Rest cardiac power $/$ mass $\geq 0.7 \mathrm{~W} / \mathrm{m}^{2}$ & \\
\hline & $\mathrm{HR}(95 \% \mathrm{Cl})$ & $\mathrm{HR}(95 \% \mathrm{Cl})$ & $P$ \\
\hline \multicolumn{4}{|l|}{ All-cause death } \\
\hline $\begin{array}{l}\text { Number of } \\
\text { cases (\%) }\end{array}$ & $331(9.38)$ & & \\
\hline Model & $1.835(1.460-2.306)$ & 1.00(Ref) & $<.001$ \\
\hline $\begin{array}{l}\text { Model + log NT- } \\
\text { proBNP }\end{array}$ & $1.753(1.394-2.203)$ & 1.00(Ref) & $\begin{array}{l}< \\
0.001\end{array}$ \\
\hline \multicolumn{4}{|l|}{$\begin{array}{l}\text { HF } \\
\text { rehospitalization }\end{array}$} \\
\hline $\begin{array}{l}\text { Number of } \\
\text { cases (\%) }\end{array}$ & $391(11.08)$ & & \\
\hline Model & $1.332(1.088-1.631)$ & 1.00(Ref) & 0.006 \\
\hline $\begin{array}{l}\text { Model + log NT- } \\
\text { proBNP }\end{array}$ & $1.266(1.033-1.551)$ & 1.00(Ref) & 0.023 \\
\hline
\end{tabular}

\subsection{Incremental value of rest cardiac power/mass for all- cause death and HF hospitalization}

We further explored the predictive value of rest cardiac power/mass by C-index (Table 4). The two indicators significantly increased the $\mathrm{C}$ statistic when they were incorporated into the established model. The individual addition of NT-proBNP or rest cardiac power/mass in the model also significantly improved the $\mathrm{C}$ statistic for predicting all-cause death and HF hospitalization. For all-cause death, the continuous NRI after the addition of rest cardiac power/mass in the model with established risk factors and NT-proBNP was $17.0 \%(95 \% \mathrm{Cl} 11.4-28.3, P=0.04)$, and the IDI was $2.3 \%(95 \% \mathrm{Cl} 0.7-8.7, P=0.02)$. For HF hospitalization, the continuous NRI after the addition of rest cardiac power/mass in the model with established risk factors and NT-proBNP was $6.0 \%(95 \% \mathrm{Cl} 4.7-15.2, P=0.026)$, and the IDI was $1.7 \%$ $(95 \% \mathrm{Cl} 1.2-4.3, P=0.007)$. 
Table 4

Reclassification and discrimination statistics for outcomes by rest cardiac power/mass

\begin{tabular}{|c|c|c|c|c|c|c|}
\hline \multirow[t]{2}{*}{ Outcomes } & \multicolumn{2}{|l|}{ C-index } & \multicolumn{2}{|l|}{$\begin{array}{l}\text { Continuous } \\
\text { NRI, \% }\end{array}$} & \multicolumn{2}{|l|}{ IDI, \% } \\
\hline & $\begin{array}{l}\text { Estimated } \\
(95 \% \mathrm{Cl})\end{array}$ & $P$ & $\begin{array}{l}\text { Estimated } \\
(95 \% \mathrm{Cl})\end{array}$ & $P$ & $\begin{array}{l}\text { Estimated } \\
(95 \% \mathrm{Cl})\end{array}$ & $P$ \\
\hline \multicolumn{7}{|l|}{ All-cause death } \\
\hline Model & $\begin{array}{l}0.741(0.712- \\
0.770)\end{array}$ & & 1.0(Ref) & & 1.0(Ref) & \\
\hline Model + log NT-proBNP & $\begin{array}{l}0.753(0.724- \\
0.781)\end{array}$ & 0.011 & $\begin{array}{l}8.0(3.0- \\
25.7)\end{array}$ & 0.013 & $\begin{array}{l}1.6(0.1- \\
3.0)\end{array}$ & 0.040 \\
\hline $\begin{array}{l}\text { Model + rest cardiac } \\
\text { power/mass }\end{array}$ & $\begin{array}{l}0.748(0.719- \\
0.777)\end{array}$ & 0.060 & $\begin{array}{l}13.8(2.4- \\
24.0)\end{array}$ & 0.020 & $\begin{array}{l}0.9(0.1- \\
1.8)\end{array}$ & 0.004 \\
\hline $\begin{array}{l}\text { Model }+ \text { log NT-proBNP + } \\
\text { rest cardiac power/mass }\end{array}$ & $\begin{array}{l}0.759(0.731- \\
0.788)\end{array}$ & 0.001 & $\begin{array}{l}17.0(11.4- \\
28.3)\end{array}$ & 0.040 & $\begin{array}{l}2.3(0.7- \\
8.7)\end{array}$ & 0.020 \\
\hline \multicolumn{7}{|l|}{ HF rehospitalization } \\
\hline Model & $\begin{array}{l}0.717(0.689- \\
0.745)\end{array}$ & & 1.0(Ref) & & 1.0(Ref) & \\
\hline Model + log NT-proBNP & $\begin{array}{l}0.747(0.721- \\
0.773)\end{array}$ & $<0.001$ & $\begin{array}{l}4.0(1.7- \\
15.0)\end{array}$ & 0.027 & $\begin{array}{l}1.3(1.2- \\
3.9)\end{array}$ & 0.077 \\
\hline $\begin{array}{l}\text { Model + rest cardiac } \\
\text { power/mass }\end{array}$ & $\begin{array}{l}0.723(0.696- \\
0.750)\end{array}$ & 0.037 & $\begin{array}{l}4.6(2.3- \\
14.9)\end{array}$ & 0.006 & $\begin{array}{l}0.5(0.1- \\
1.5)\end{array}$ & 0.058 \\
\hline $\begin{array}{l}\text { Model + log NT-proBNP + } \\
\text { rest cardiac power/mass }\end{array}$ & $\begin{array}{l}0.749(0.723- \\
0.775)\end{array}$ & $<0.001$ & $\begin{array}{l}6.0(4.7- \\
15.2)\end{array}$ & 0.026 & $\begin{array}{l}1.7(1.2- \\
4.3)\end{array}$ & 0.007 \\
\hline
\end{tabular}

\subsection{Rest cardiac power/mass as independent predictor of outcome}

Rest cardiac power/mass was independently associated with all-cause death across most patient subgroups (Fig. 4). Similarly, it presented independent prognostic value for HF hospitalization in multiple subsets (Fig. 5). Combining with results in Table 3, sensitivity analysis indicated rest cardiac power/mass as an independent predictor for adverse outcomes in patients with stable HFpEF.

\section{Discussion}


We for the first time investigated the role of cardiac power estimated by non-invasive echocardiography in patients with stable HFpEF. In this study, we found that (i) cardiac power normalized to LV mass at rest were both independently associated with all-cause death and HF hospitalization in patients with HFpEF and (ii) the incorporation of rest cardiac power/mass (reflective of comprehensive cardiac function) and NT-proBNP (indicative of myocardial stretch) into a model with established risk factors enhanced the prognostic value for the endpoints.

As is well known, LV diastolic dysfunction plays a fundamental and predominant role in the pathophysiology of HFpEF [10] and elevates filling pressure, which further promotes dyspnea, impairs exercise capacity and increases mortality and incidence for HF hospitalization[11]. Non-invasive echocardiography is an indirect approach to measuring LV diastolic function. Due to its safety and rapidity, echocardiography is usually superior to the invasive right heart catheterization for clinical physicians. However, individual parameters of echocardiography, such as left atrial volume index and the mitral annular diastolic velocity, has their own limitations and fail to accurately determine LV dysfunction as well as the severity. Moreover, a combination of these parameters undoubtedly increases the work burden and is not conducive to clinical application.

Despite having a "preserved" EF, HFpEF also presents abnormity in LV systolic performance [12, 13]. Multiple studies have demonstrated that patients with HFpEF present subtle impairments in systolic function at rest, and this alternation tends to expand during exertion, which impairs LV suction, decreases cardiac output, and elevates LV filling pressures $[14,15]$. LV systolic dysfunction in HFpEF also predict increased risk of adverse outcomes $[16,17]$. Some scholars question the ability of EF to truly reflect the LV systolic function of HFpEF[18]. HFpEF patients are often complicated with myocardial concentric hypertrophy, which inevitably generates a normal or supernormal $E F$, even when stroke volume is declined. Therefore, a non-invasive method which can quantify LV pump function better than EF and would be a major step forward.

Cardiac power is a comprehensive quantitative indicator and can evaluate cardiac function via noninvasive echocardiography $[4,5,19]$. It is better than variables such as cardiac output because it covers both pressure load and volume load[20]. Since the power depends on the volume of the muscle that produces the power, standardizing cardiac power with LV mass can better evaluate the applicability of this indicator in different populations $[4,6,19]$, and also facilitate the comparison between individuals. In addition, cardiac power may be more promising than EF. It has been reported to be the strongest predictor of in-hospital mortality in patients with cardiac shock because of acute myocardial infarction [20], and presently have been used to evaluate the response of patients with advanced HF to mechanical circulatory support system [21].

In the present study, we found that the HFpEF patients with lower rest cardiac power/mass were more likely to be older and had higher NYHA class and NT-proBNP level, as well as more comorbidities, indicating that the patients in this subgroup might have a worse baseline condition and more risk factors of adverse outcomes. After adjustment of multiple covariates, such as age and comorbidity, our study 
brought new evidence that rest cardiac power/mass were independently associated with all-cause death and HF hospitalization in patients with HFpEF. Meanwhile, rest cardiac power/mass significantly promoted the prediction efficiency of both traditional risk factors and NT-proBNP, supporting a pathophysiological link between the reduced cardiac performance and the mortality and HF progression later on in life as aging and comorbidities advance. Furthermore, we performed sensitivity analysis, and the results showed that although not all subgroups showed a statistically significant association, the risk of adverse outcome within these subgroups was higher in patients with lower rest cardiac power/mass than in those with higher rest cardiac power/mass, indicating the stable and independent prediction efficacy of rest cardiac power/mass among HFpEF patients. Clinically, rest cardiac power/mass is easily obtained by measuring blood pressure and stroke volume. And the latter can be measured by Doppler echocardiography. What is more excitingly is that the technical setup of cardiac power is very similar to what is used in a standard diastolic stress test, so whether the integrated application of the two tests provides incremental diagnostic or prognostic significance in HFpEF patients deserves further exploration.

Our study has some limitations: (1) this study is a retrospective study design; (2) compared to invasive measurements, the non-invasive measurements of stroke volume may be inclined to errors; and (3) the prognostic value of peak or reserved cardiac power indexed to LV mass is not evaluated in patients with HFpEF.

\section{Conclusions}

To conclude, our study explored the association between rest cardiac power/mass and the risk of allcause death and HF hospitalization in patients with HFpEF, finding that lower rest cardiac power/mass is an independent predictor of the adverse outcomes and also have incremental prognostic value over established risk factors and NT-proBNP. Cardiac power as an integrated indicator of cardiac performance may be considered for risk stratification of long-term adverse outcomes in patients with HFpEF. It helps to provide more comprehensive and accurate guidance to the treatment and prognostic evaluation for HFpEF patients, and further promote the integration and optimization of cardiac function monitoring indicators.

\section{Declarations}

Ethics approval and consent to participate

This study was approved by the Ethics Board of the Chinese PLA General Hospital and written informed consent was obtained from each patient.

\section{Consent for publication}

Not applicable. 
Availability of data and materials

The datasets used and/or analyzed during the current study are available from the corresponding author on reasonable request.

\section{Competing of interests}

The authors declare that they have no known competing financial interests or personal relationships that could have appeared to influence the work reported in this paper.

\section{Funding}

This work was supported by the Key Projects of Logistics Scientific Research Project of Chinese PLA (17BJZ48).

\section{Authors' contribution}

$\mathrm{JC}$ and $\mathrm{HL}$ designed the protocol and provided methodological expertise.; JC drafted the manuscript; $\mathrm{HL}$ and $\mathrm{YC}$ supervised patient recruitment and study procedures; $\mathrm{BH}$ conducted study procedures; JC and SW performed statistical analyses. All authors read and approved the final manuscript.

\section{Acknowledgment}

Not applicable.

\section{References}

1. Steinberg BA, Zhao X, Heidenreich PA, Peterson ED, Bhatt DL, Cannon CP, et al. Trends in patients hospitalized with heart failure and preserved left ventricular ejection fraction: prevalence, therapies, and outcomes. Circulation. 2012;126(1):65-75.

2. Redfield MM. Heart Failure with Preserved Ejection Fraction. N Engl J Med. 2016;375(19):1868-77.

3. Nicholls DP, O'Dochartaigh C, Riley MS. Circulatory power-a new perspective on an old friend. Eur Heart J. 2002;23(16):1242-5.

4. Cortigiani L, Sorbo S, Miccoli M, Scali MC, Simioniuc A, Morrone D, et al. Prognostic value of cardiac power output to left ventricular mass in patients with left ventricular dysfunction and dobutamine stress echo negative by wall motion criteria. Eur Heart J Cardiovasc Imaging. 2017;18(2):153-8.

5. Lang CC, Karlin P, Haythe J, Lim TK, Mancini DM. Peak cardiac power output, measured noninvasively, is a powerful predictor of outcome in chronic heart failure. Circ Heart Fail. 2009;2(1):33-8.

6. Dini FL, Mele D, Conti U, Ballo P, Citro R, Menichetti F, et al. Peak power output to left ventricular mass: an index to predict ventricular pumping performance and morbidity in advanced heart failure. $\mathrm{J} \mathrm{Am}$ Soc Echocardiogr. 2010;23(12):1259-65. 
7. Anand V, Kane GC, Scott CG, Pislaru SV, Adigun RO, McCully RB, et al. Prognostic value of peak stress cardiac power in patients with normal ejection fraction undergoing exercise stress echocardiography. Eur Heart J. 2021;42(7):776-85.

8. Ponikowski P, Voors AA, Anker SD, Bueno Hc, Cleland JGF, Coats AJS, et al. 2016 ESC Guidelines for the diagnosis and treatment of acute and chronic heart failure: The Task Force for the diagnosis and treatment of acute and chronic heart failure of the European Society of Cardiology (ESC)Developed with the special contribution of the Heart Failure Association (HFA) of the ESC. Eur Heart J 2016, 37(27):2129-2200.

9. Charlson ME, Pompei P, Ales KL, MacKenzie CR. A new method of classifying prognostic comorbidity in longitudinal studies: development and validation. Journal of chronic diseases. 1987;40(5):37383.

10. Borlaug BA. The pathophysiology of heart failure with preserved ejection fraction. Nat Rev Cardiol. 2014;11(9):507-15.

11. Reddy YNV, Olson TP, Obokata M, Melenovsky V, Borlaug BA. Hemodynamic Correlates and Diagnostic Role of Cardiopulmonary Exercise Testing in Heart Failure With Preserved Ejection Fraction. JACC Heart failure. 2018;6(8):665-75.

12. Obokata M, Reddy YNV, Borlaug BA. Diastolic Dysfunction and Heart Failure With Preserved Ejection Fraction: Understanding Mechanisms by Using Noninvasive Methods. JACC Cardiovasc Imaging. 2020;13:245-57.

13. Abudiab MM, Redfield MM, Melenovsky V, Olson TP, Kass DA, Johnson BD, et al. Cardiac output response to exercise in relation to metabolic demand in heart failure with preserved ejection fraction. Eur J Heart Fail. 2013;15(7):776-85.

14. Reddy YNV, Andersen MJ, Obokata M, Koepp KE, Kane GC, Melenovsky V, et al. Arterial Stiffening With Exercise in Patients With Heart Failure and Preserved Ejection Fraction. J Am Coll Cardiol. 2017;70(2):136-48.

15. Borlaug BA, Kane GC, Melenovsky V, Olson TP. Abnormal right ventricular-pulmonary artery coupling with exercise in heart failure with preserved ejection fraction. Eur Heart J. 2016;37(43):3293-302.

16. Borlaug BA, Lam CSP, Roger VrL, Rodeheffer RJ, Redfield MM. Contractility and ventricular systolic stiffening in hypertensive heart disease insights into the pathogenesis of heart failure with preserved ejection fraction. J Am Coll Cardiol. 2009;54(5):410-8.

17. Shah AM, Claggett B, Sweitzer NK, Shah SJ, Anand IS, Liu L, et al. Prognostic Importance of Impaired Systolic Function in Heart Failure With Preserved Ejection Fraction and the Impact of Spironolactone. Circulation. 2015;132(5):402-14.

18. Smiseth $\mathrm{OA}$, Aalen JM, Skulstad $\mathrm{H}$. Heart failure and systolic function: time to leave diagnostics based on ejection fraction? Eur Heart J. 2021;42(7):786-8.

19. Pugliese NR, Fabiani I, Mandoli GE, Guarini G, Galeotti GG, Miccoli M, et al. Echo-derived peak cardiac power output-to-left ventricular mass with cardiopulmonary exercise testing predicts outcome in 
patients with heart failure and depressed systolic function. Eur Heart $\mathrm{J}$ Cardiovasc Imaging. 2019;20(6):700-8.

20. Fincke $u$, Hochman JS, Lowe AM, Menon V, Slater JN, Webb JG, et al. Cardiac power is the strongest hemodynamic correlate of mortality in cardiogenic shock: a report from the SHOCK trial registry. $\mathrm{J}$ Am Coll Cardiol. 2004;44(2):340-8.

21. Rab T, Ratanapo S, Kern KB, Basir MB, McDaniel M, Meraj P, et al. Cardiac Shock Care Centers: JACC Review Topic of the Week. J Am Coll Cardiol. 2018;72(16):1972-80.

\section{Tables}

Table 1 Baseline characteristics of patients with HFpEF 


\begin{tabular}{|c|c|c|c|}
\hline & $\begin{array}{l}\text { Rest cardiac power } / \text { mass }<0.7 \\
\mathrm{~W} / \mathrm{m}^{2}(\mathrm{~N}=1021)\end{array}$ & $\begin{array}{l}\text { Rest cardiac power/mass } \geq 0.7 \\
\mathrm{~W} / \mathrm{m}^{2}(\mathrm{~N}=1068)\end{array}$ & $\begin{array}{l}P- \\
\text { value }\end{array}$ \\
\hline Age (years) & $77.90 \pm 11.37$ & $74.78 \pm 11.39$ & 0.046 \\
\hline Male (\%) & $983(96.28)$ & 1018(95.32) & 0.163 \\
\hline Smoking (\%) & $376(37.12)$ & $386(36.28)$ & 0.363 \\
\hline Alcohol (\%) & $326(32.06)$ & $339(31.83)$ & 0.475 \\
\hline WC $(\mathrm{cm})$ & $92.23 \pm 8.77$ & $92.30 \pm 8.65$ & 0.487 \\
\hline $\mathrm{BMI}\left(\mathrm{kg} / \mathrm{m}^{2}\right)$ & $24.48 \pm 2.93$ & $24.52 \pm 3.21$ & 0.476 \\
\hline $\mathrm{SBP}(\mathrm{mmHg})$ & $128.665 \pm 16.722$ & $137.396 \pm 16.603$ & 0.648 \\
\hline $\mathrm{DBP}(\mathrm{mmHg})$ & $66.66 \pm 8.80$ & $75.41 \pm 9.50$ & 0.048 \\
\hline HR (bpm) & $66.56 \pm 8.50$ & $77.10 \pm 10.49$ & $<0.001$ \\
\hline NYHA class & & & 0.031 \\
\hline I or II & $594(58.18)$ & $656(61.42)$ & \\
\hline III or IV & $427(41.82)$ & $412(38.58)$ & \\
\hline $\begin{array}{l}\text { eGFR } \\
(\mathrm{mL} / \mathrm{min} / 1.73 \\
\left.\mathrm{m}^{2}\right)\end{array}$ & $87.79 \pm 24.94$ & $90.36 \pm 23.52$ & 0.572 \\
\hline FBG (mmol/L) & $5.78 \pm 1.61$ & $5.81 \pm 1.72$ & 0.789 \\
\hline $\begin{array}{l}\text { Log NT-proBNP } \\
(\mathrm{pg} / \mathrm{mL})\end{array}$ & $2.45 \pm 0.56$ & $2.30 \pm 0.55$ & $<0.001$ \\
\hline $\begin{array}{l}\text { Comorbidity } \\
\text { score }\end{array}$ & $3.52 \pm 1.90$ & $3.15 \pm 1.81$ & 0.015 \\
\hline \multicolumn{4}{|l|}{ Medication (\%) } \\
\hline ACEI/ARB & $379(37.12)$ & $370(34.64)$ & 0.128 \\
\hline Beta blocker & $292(28.60)$ & $308(28.84)$ & 0.471 \\
\hline Diuretic & 154(15.08) & $101(9.46)$ & $<0.001$ \\
\hline Statins & $701(68.66)$ & $626(58.61)$ & $<0.001$ \\
\hline $\begin{array}{l}\text { Aldosterone } \\
\text { antagonist }\end{array}$ & $49(4.80)$ & $32(3.00)$ & 0.021 \\
\hline
\end{tabular}

Data are expressed as mean + SD or median and number (\%). HFpEF indicates heart failure with preserved ejection fraction; WC, waist circumference; BMI, body mass index; SBP, systolic blood pressure; DBP, diastolic blood pressure; HR, heart rate; NYHA, New York Heart Association; eGFR, estimated 
glomerular filtration rate; FBG, fasting blood glucose; NT-proBNP, N-terminal pro-brain natriuretic peptide; ACEl, angiotensin-converting enzyme inhibitors; ARB, angiotensin receptor antagonist.

Table 2 Spearman's correlation and multiple linear regression between rest cardiac power/mass and clinical and biochemical variables

\begin{tabular}{|lllll|}
\hline Variables & \multicolumn{2}{c}{ Spearman correlation } & \multicolumn{2}{l|}{ Multiple linear regression } \\
\hline & Coefficient & $P$ & Standardized $\beta$ & $P$ \\
\hline Age (years) & -0.155 & $<0.001$ & -0.063 & 0.039 \\
\hline Male & -0.024 & 0.271 & -0.042 & 0.063 \\
\hline Smoking & 0.015 & 0.499 & 0.007 & 0.771 \\
\hline Alcohol & 0.015 & 0.493 & 0.019 & 0.433 \\
\hline WC (cm) & 0.024 & 0.283 & 0.020 & 0.387 \\
\hline BMI (kg/m $\left.{ }^{2}\right)$ & -0.042 & 0.058 & -0.045 & 0.056 \\
\hline SBP (mmHg) & 0.015 & 0.501 & 0.006 & 0.805 \\
\hline DBP (mmHg) & 0.026 & 0.236 & 0.020 & 0.437 \\
\hline HR (bpm) & 0.008 & 0.710 & 0.023 & 0.316 \\
\hline NYHA class & -0.042 & 0.053 & 0.010 & 0.674 \\
\hline eGFR (mL/min/1.73m $\left.{ }^{2}\right)$ & 0.086 & $<0.001$ & 0.005 & 0.830 \\
\hline FBG (mmol/L) & 0.067 & 0.002 & 0.073 & 0.201 \\
\hline Log NT-proBNP (pg/mL) & -0.162 & $<0.001$ & -0.102 & $<0.001$ \\
\hline Comorbidity score & -0.138 & $<0.001$ & -0.062 & 0.028 \\
\hline Medication (\%) & & & & 0.0106 \\
\hline ACEl/ARB & -0.051 & 0.02 & -0.028 & 0.994 \\
\hline Beta blocker & -0.004 & 0.856 & 0.057 & 0.006 \\
\hline Diuretic & -0.011 & 0.630 & -0.062 & 0.014 \\
\hline Statins & 0.029 & 0.184 & 0.000 & -0.062 \\
\hline Aldosterone antagonist & -0.084 & $<0.001$ & & \\
\hline
\end{tabular}

Abbreviations are same as Table 1.

Table $3 \mathrm{HRs}$ and $95 \%$ Cls of outcomes according to the categories of rest cardiac power/mass 


\begin{tabular}{|c|c|c|c|}
\hline Outcomes & $\begin{array}{l}\text { Rest cardiac power/mass } \\
\leq 0.7 \mathrm{~W} / \mathrm{m}^{2}\end{array}$ & Rest cardiac power/mass $\geq 0.7 \mathrm{~W} / \mathrm{m}^{2}$ & \\
\hline & $\mathrm{HR}(95 \% \mathrm{Cl})$ & $\mathrm{HR}(95 \% \mathrm{Cl})$ & $P$ \\
\hline \multicolumn{4}{|l|}{ All-cause death } \\
\hline $\begin{array}{l}\text { Number of } \\
\text { cases (\%) }\end{array}$ & $331(9.38)$ & & \\
\hline Model & $1.835(1.460-2.306)$ & 1.00(Ref) & $<0.001$ \\
\hline $\begin{array}{l}\text { Model + log NT- } \\
\text { proBNP }\end{array}$ & $1.753(1.394-2.203)$ & 1.00(Ref) & $<0.001$ \\
\hline \multicolumn{4}{|l|}{$\begin{array}{l}\text { HF } \\
\text { rehospitalization }\end{array}$} \\
\hline $\begin{array}{l}\text { Number of cases } \\
(\%)\end{array}$ & 391(11.08) & & \\
\hline Model & $1.332(1.088-1.631)$ & 1.00 (Ref) & 0.006 \\
\hline $\begin{array}{l}\text { Model + log NT- } \\
\text { proBNP }\end{array}$ & $1.266(1.033-1.551)$ & 1.00 (Ref) & 0.023 \\
\hline
\end{tabular}

Model: Age, sex, BMI, NYHA class, comorbidity score, eGFR, ACEI/ARB, beta blocker and aldosterone antagonist. HR, hazard ratio; $\mathrm{Cl}$, confidence interval; other abbreviations are same as Table 1.

Table 4 Reclassification and discrimination statistics for outcomes by rest cardiac power/mass 


\begin{tabular}{|c|c|c|c|c|c|c|}
\hline Outcomes & C-index & & $\begin{array}{l}\text { Continuous } \\
\text { NRI, \% }\end{array}$ & & IDI, \% & \\
\hline & $\begin{array}{l}\text { Estimated } \\
(95 \% \mathrm{Cl})\end{array}$ & $P$ & $\begin{array}{l}\text { Estimated } \\
(95 \% \mathrm{Cl})\end{array}$ & $P$ & $\begin{array}{l}\text { Estimated } \\
(95 \% \mathrm{Cl})\end{array}$ & $\mathrm{P}$ \\
\hline \multicolumn{7}{|l|}{ All-cause death } \\
\hline Model & $\begin{array}{l}0.741(0.712- \\
0.770)\end{array}$ & & 1.0(Ref) & & 1.0(Ref) & \\
\hline Model + log NT-proBNP & $\begin{array}{l}0.753(0.724- \\
0.781)\end{array}$ & 0.011 & $\begin{array}{l}8.0(3.0- \\
25.7)\end{array}$ & 0.013 & $\begin{array}{l}1.6(0.1- \\
3.0)\end{array}$ & 0.040 \\
\hline $\begin{array}{l}\text { Model + rest cardiac } \\
\text { power/mass }\end{array}$ & $\begin{array}{l}0.748(0.719- \\
0.777)\end{array}$ & 0.060 & $\begin{array}{l}13.8(2.4- \\
24.0)\end{array}$ & 0.020 & $\begin{array}{l}0.9(0.1- \\
1.8)\end{array}$ & 0.004 \\
\hline $\begin{array}{l}\text { Model + log NT-proBNP } \\
\text { +rest cardiac power/mass }\end{array}$ & $\begin{array}{l}0.759(0.731- \\
0.788)\end{array}$ & 0.001 & $\begin{array}{l}17.0(11.4- \\
28.3)\end{array}$ & 0.040 & $\begin{array}{l}2.3(0.7- \\
8.7)\end{array}$ & 0.020 \\
\hline \multicolumn{7}{|l|}{ HF rehospitalization } \\
\hline Model & $\begin{array}{l}0.717(0.689- \\
0.745)\end{array}$ & & 1.0(Ref) & & 1.0(Ref) & \\
\hline Model + log NT-proBNP & $\begin{array}{l}0.747(0.721- \\
0.773)\end{array}$ & $<0.001$ & $\begin{array}{l}4.0(1.7- \\
15.0)\end{array}$ & 0.027 & $\begin{array}{l}1.3(1.2- \\
3.9)\end{array}$ & 0.077 \\
\hline $\begin{array}{l}\text { Model + rest cardiac } \\
\text { power/mass }\end{array}$ & $\begin{array}{l}0.723(0.696- \\
0.750)\end{array}$ & 0.037 & $\begin{array}{l}4.6(2.3- \\
14.9)\end{array}$ & 0.006 & $\begin{array}{l}0.5(0.1- \\
1.5)\end{array}$ & 0.058 \\
\hline $\begin{array}{l}\text { Model + log NT-proBNP } \\
\text { +rest cardiac power/mass }\end{array}$ & $\begin{array}{l}0.749(0.723- \\
0.775)\end{array}$ & $<0.001$ & $\begin{array}{l}6.0(4.7- \\
15.2)\end{array}$ & 0.026 & $\begin{array}{l}1.7(1.2- \\
4.3)\end{array}$ & 0.007 \\
\hline
\end{tabular}

Model: Age, sex, BMI, NYHA class, comorbidity score, eGFR, ACEI/ARB, beta blocker and aldosterone antagonist. HR, hazard ratio; $\mathrm{Cl}$, confidence interval; NRI, net re-classification improvement; IDI, integrated discrimination improvement; other abbreviations are same as Table 1.

\section{Figures}




\section{3 community dwellers}

1434 without HFpEF excluded

326 with missing information excluded

42 with metastasis tumor excluded

35 with expected survival time less than 6 months excluded

17 with palliative care excluded

\section{9 eligible HFpEF patients in the final study}

\section{Figure 1}

Flowchart of the data process 

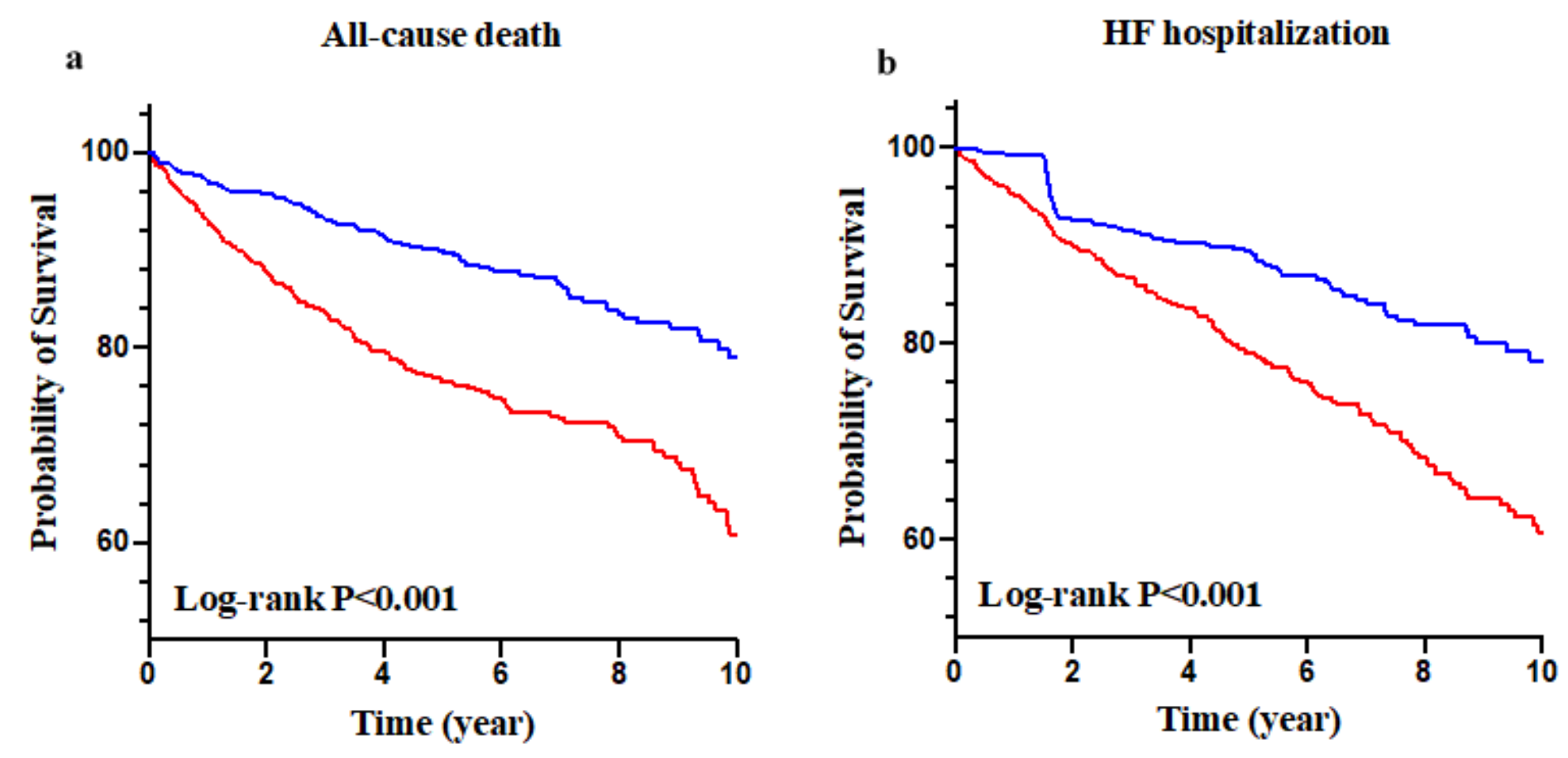

- Rest cardiac power $/$ mass $>0.7 \mathrm{~W} / \mathrm{m}^{2}$
- Rest cardiac power $/ \mathrm{mass} \leq 0.7 \mathrm{~W} / \mathrm{m}^{2}$

Figure 2

Kaplan-Meier curves for prediction of all-cause death (a) and HF hospitalization (b) in patients with higher rest cardiac power/mass $(\geq 0.7 \mathrm{~W} / \mathrm{m} 2)$ and lower rest cardiac power/mass $(<0.7 \mathrm{~W} / \mathrm{m} 2)$ 


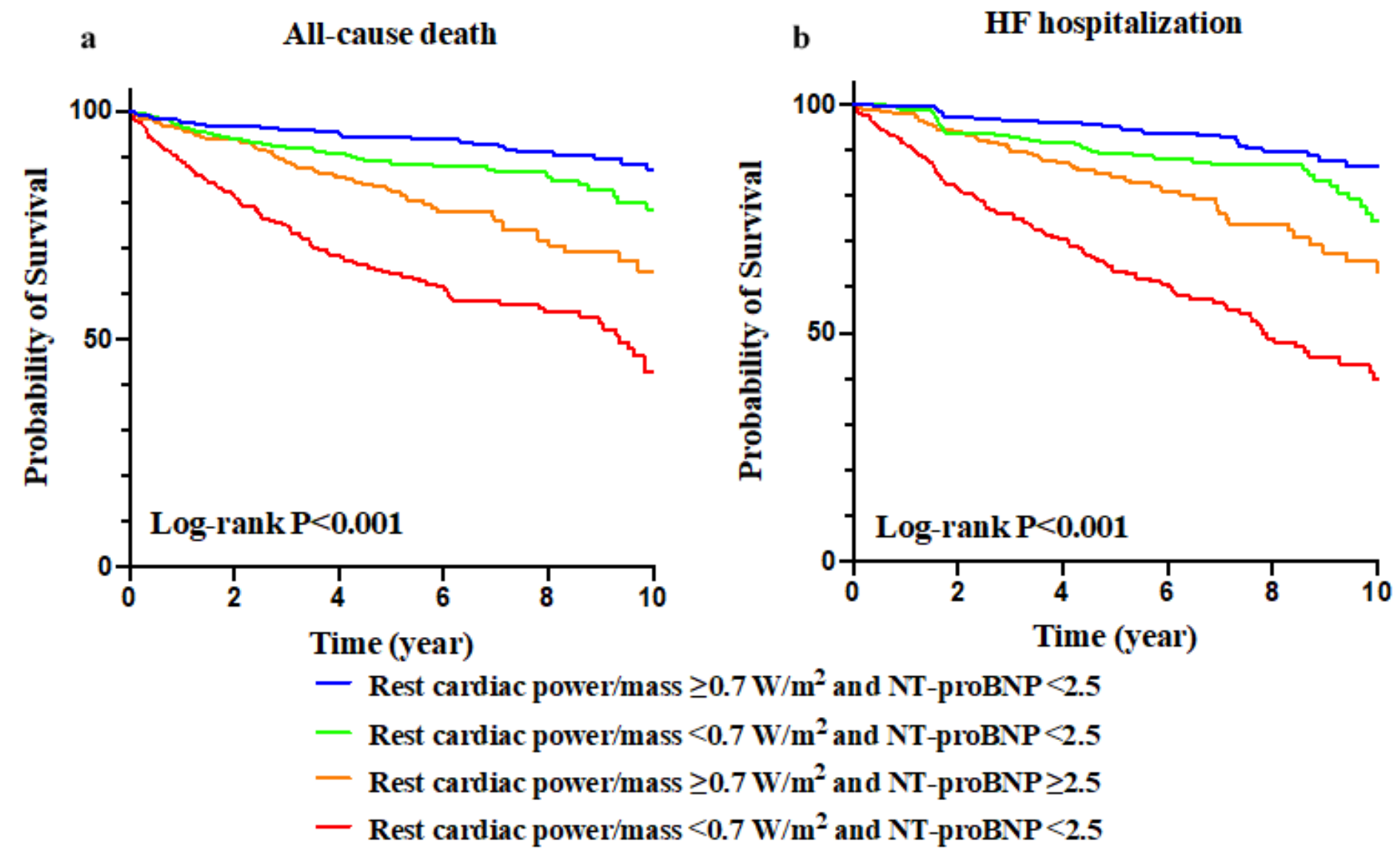

Figure 3

Kaplan-Meier survival curves for prediction of all-cause death (A) and HF hospitalization (B) according to rest cardiac power/mass and NT-proBNP levels 


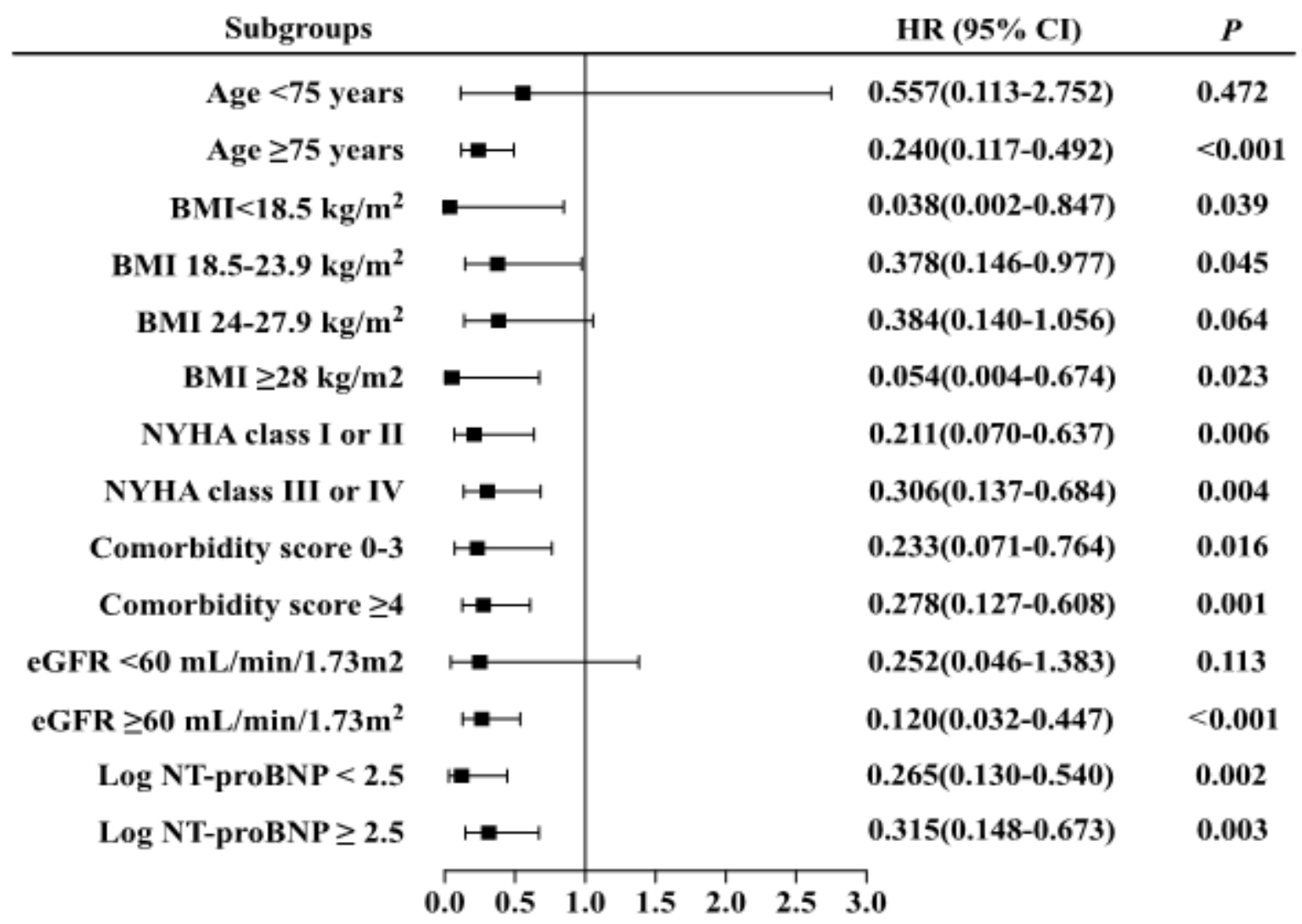

Figure 4

Rest cardiac power/mass for the prediction of all-cause death: subgroup analysis The prognostic value of rest cardiac power/mass is considered in several patient subgroups, after adjustment for age, sex, BMI, NYHA class, comorbidity score, eGFR, log NT-proBNP, ACEI/ARB, beta blocker and aldosterone antagonist. Other abbreviations as in Table 1. 
Rest cardiac power/mass and $\mathrm{HF}$ hospitalization

\begin{tabular}{|c|c|c|c|}
\hline Subgroups & & HR $(95 \% \mathrm{CI})$ & $P$ \\
\hline Age $\geq 75$ years & $H$ & $0.241(0.063-0.924)$ & 0.038 \\
\hline Age $<75$ years & -1 & $0.567(0.296-1.088)$ & 0.088 \\
\hline $\mathrm{BMI}<18.5 \mathrm{~kg} / \mathrm{m}^{2}$ & $H$ & $0.135(0.002-0.657)$ & 0.031 \\
\hline BMII $18.5-23.9 \mathrm{~kg} / \mathrm{m}^{2}$ & $\mapsto$ & $0.403(0.166-0.981)$ & 0.045 \\
\hline BMI $24-27.9 \mathrm{~kg} / \mathrm{m}^{2}$ & & $0.633(0.252-1.592)$ & 0.331 \\
\hline $\mathrm{BMI} \geq 28 \mathrm{~kg} / \mathrm{m} 2$ & $\longmapsto$ & $0.315(0.033-2.970)$ & 0.313 \\
\hline NYHA class I or II & $\mapsto$ & $0.326(0.131-0.810)$ & 0.016 \\
\hline NYHA class III or IV & $\longrightarrow$ & $0.603(0.280-1.300)$ & 0.197 \\
\hline Comorbidity score $0-3$ & $\mapsto$ & $0.331(0.118-0.932)$ & 0.036 \\
\hline Comorbidity score $\geq 4$ & -1 & $0.555(0.272-1.136)$ & 0.107 \\
\hline $\mathrm{eGFR}<60 \mathrm{~mL} / \mathrm{min} / 1.73 \mathrm{~m} 2$ & $\longrightarrow$ & $0.232(0.041-1.306)$ & 0.097 \\
\hline $\mathrm{eGFR} \geq 60 \mathrm{~mL} / \mathrm{min} / 1.73 \mathrm{~m}^{2}$ & & $0.530(0.282-0.994)$ & 0.048 \\
\hline Log NT-proBNP $<2.5$ & & $0.994(0.329-3.002)$ & 0.991 \\
\hline Log NT-proBNP $\geq 2.5$ & $\mapsto$ & $0.360(0.180-0.720)$ & 0.004 \\
\hline
\end{tabular}

Figure 5

Rest cardiac power/mass for the prediction of HF rehospitalization: subgroup analysis The prognostic value of rest cardiac power/mass is considered in several patient subgroups, after adjustment for age, sex, BMI, NYHA class, comorbidity score, eGFR, log NT-proBNP, ACEI/ARB, beta blocker and aldosterone antagonist. Other abbreviations as in Table 1. 